Fernando Donato Vasconcelos ${ }^{1}$

\begin{abstract}
${ }^{1}$ Ministério do Trabalho e Emprego.
* O trabalho foi atualizado a partir da tese de doutoramento em Saúde Pública Ironias da desigualdade: políticas e práticas de inclusão de pessoas com deficiência física, apresentada e aprovada no Instituto de Saúde Coletiva da Universidade Federal da Bahia, em 2005. Versão em poster do artigo foi apresentada no Congresso Mundial de Saúde Pública, em Istambul, em 2009.
\end{abstract}

Contato:

Fernando Donato Vasconcelos Ministério do Trabalho e Emprego Departamento de Segurança e Saúde no Trabalho - DSST

Esplanada dos Ministérios Bloco F-Anexo - Sala 145

Brasília-DF

CEP: 70059-900

E-mail:

fdvasconcelos@gmail.com

Recebido: 22/06/2009

Revisado: 19/03/2010

Aprovado: 23/03/2010

\section{O trabalhador com deficiência e as práticas de inclusão no mercado de trabalho de Salvador, Bahia*}

\author{
Workers with disability and process for their inclusion in the \\ labor market in Salvador, Bahia, Brazil
}

\section{Resumo}

O autor analisou políticas e práticas de inclusão da pessoa com deficiência física no mercado de trabalho em Salvador, Bahia. Considera que a deficiência é, acima de tudo, um produto social, e que as estratégias de inclusão no trabalho adotadas no Brasil são insuficientes, não levando em conta aspectos relevantes do complexo mundo do trabalho e dos sujeitos envolvidos. Foram realizadas, em 2003, entrevistas semiestruturadas com 22 deficientes físicos, 6 chefes e colegas desses trabalhadores com deficiência, assim como 7 técnicos e dirigentes de instituições relacionadas à deficiência, totalizando 35 entrevistas. Foram feitas revisão de documentos e estatísticas e visitas a instituições. O autor constatou que o sistema de cotas de emprego tem se destacado principalmente pela discussão que traz sobre o tema do direito ao trabalho das pessoas com deficiência. Identificou que as estratégias e práticas de inclusão estão marcadas por situações que denomina de "ironias da desigualdade”, como, por exemplo, a ameaça de chefes a empregados, obrigando-os a tratar os "deficientes" como "normais", a visão da deficiência como virtude, por facilitar o acesso ao emprego, e a utilização do deficiente como exemplo de "bom trabalhador" e fator de disciplinamento, em razão da sua superação de limites.

Palavras-chave: pessoas com deficiência; saúde do trabalhador; iniquidade social; trabalho; políticas públicas.

\begin{abstract}
The author analyzes inclusion polices and practices for workers with disability within the labor market in Salvador, Bahia, Brazil. Disability is above all a social product, and work inclusion strategies adopted in Brazil are inadequate as they do not take into account relevant aspects of the world of labor and of the actors involved in it. In 2003, thirty five interviews were conducted with 22 workers with physical disability, six of their superiors and co-workers, and seven professionals and leaders of institutions concerned with workers' disability. Specific legislation and employment statistics were analyzed, and institutions were visited, evidencing that the quota system for employment is not sufficient to ensure reasonable number of jobs for workers with disability. The author identified that inclusion strategies and practices are marked by situations that could be called "inequality ironies", as, for example, the fact that superiors at work compel employees to treat "persons with disability" as "normal people"; that disability is considered as a "virtue", as it facilitates job access; that workers with disability are used as examples of "good workers" and discipline, due to their ability to overcome limitations.
\end{abstract}

Keywords: people with disabilities; occupational health; social inequality; work; public policies. 


\section{Introdução}

Não é a existência de uma lesão ou da incapacidade que faz com que uma pessoa seja deficiente, mas, sim, a forma como a sociedade possibilita meios para sua inclusão e para garantir o seu "direito de estar no mundo". Todavia, especialmente na definição de políticas públicas, tem-se verificado que a deficiência "pressupõe a existência de variações de algumas habilidades que sejam qualificadas como restrições ou lesões" (DINIZ; SQUINCA; MEDEIROS, 2007).

A concepção da sociedade enquanto um mercado de trabalho é um dos elementos centrais da crescente exclusão social (DRACHE, 2004), que atinge expressivos segmentos da sociedade, geralmente com pouca representação política e raras oportunidades de acesso ao trabalho. Tal exclusão se expressa, ainda, em barreiras culturais, educacionais, étnicas, econômicas e arquitetônicas, criando restrições por: classe, gênero, raça, religião, ideologia e capacidade física ou mental.

Ao estudar a inserção de pessoas com deficiência no trabalho, Costa (2001a) afirma que a condição humana é duplamente negada a este trabalhador, pois, antes mesmo de acessar o mercado, são-lhe criados obstáculos para se inserir no mundo do trabalho, pois, supostamente, faltar-lhe-iam a competência e a habilidade, consideradas imprescindíveis pelo capital.

É frequente que o adolescente ou o jovem com deficiência trace "projetos de futuro" menos ambiciosos ao se deparar com as restrições de ingresso no mercado de trabalho (BASTOS, 2002), o que é particularmente importante nessa fase da vida, pois o trabalho pode ser um meio da pessoa com deficiência desenvolver um sentimento de "pertencimento" à sociedade, aumentando sua autoestima e sua segurança no enfrentamento das barreiras sociais (COSTA, 2001b).

Quem não tem “alguma capacidade especial” está condenado à exclusão (BAUMAN, 2003). A elaboração de políticas denominadas afirmativas visa permitir o acesso de uma minoria excluída ao trabalho e é uma forma de reduzir os efeitos de tal sistema de desigualdade. A política de inclusão de pessoas com deficiência no trabalho, no Brasil, seguindo uma tendência mundial, baseia-se na obrigatoriedade de um sistema de cotas e tem tido resultados importantes, não tanto em relação ao número de pessoas que obtêm o emprego formal, mas na discussão do tema do direito ao trabalho dessas pessoas.

A reserva de cotas para deficientes surgiu primeiramente na Áustria, na Alemanha, na França e na Itália para atender acordos após a I Grande Guerra e recomendações da recém-criada Organização Internacional do Trabalho (OIT), assegurando certa percentagem de postos de trabalho para veteranos de guerra deficientes. Havia um sistema de penalidades para aqueles que não as cumprissem. Posteriormente, as cotas passaram a incorporar pessoas acidentadas no trabalho e, após a II Grande Guerra, Reino Unido, Holanda, Irlanda,
Bélgica, Grécia e Espanha adotaram sistemas de cotas mais amplos, abrangendo outros tipos de deficiência (METTS, 2000).

Tal ampliação trouxe também desgaste para o sistema, porque cresceu muito a demanda por esse tipo de emprego protegido e muitas empresas não tinham condições de absorver todos os tipos de deficiência sem o apoio do Estado, em razão do que as penalidades passaram a ser desacreditadas. Outro problema também referido em relação ao sistema de cotas foi o fato de trabalhadores bem qualificados, porém deficientes, serem discriminados por terem ingressado através da cota.

$\mathrm{Na}$ última década do século XX, o Reino Unido deixou o sistema de cotas, enquanto Holanda, Portugal, Irlanda, Bélgica, Alemanha e França reformaram os seus sistemas. Atualmente, contudo, o sistema de cotas ainda persiste em metade da União Europeia e muitos países emergentes em todo o mundo passaram a adotá-lo (METTS, 2000).

Os Estados Unidos não adotam o sistema de cotas, mas a sua norma antidiscriminatória (ADA - Americans with Disabilities Act), criada há mais de duas décadas, abrange outros aspectos dos direitos civis, além do direito ao trabalho (FRANCIS; SILVERS, 2000), uma vez que foi fortemente influenciada pelos movimentos sociais da década de 1960, naquele país.

Embora já houvesse iniciativas anteriores e as normas constitucionais de 1988, o sistema de cotas para trabalhadores com deficiência no Brasil foi delineado a partir de dezembro de 1991, com a promulgação da Lei 8.213, que tratou dos benefícios da previdência social e incluiu, no seu artigo 93, que as empresas com 100 ou mais empregados passavam a ser obrigadas a preencher de $2 \%$ a $5 \%$ dos seus cargos com beneficiários reabilitados ou pessoas com deficiência habilitadas, $2 \%$ na faixa de 100 a 200 empregados; 3\%, de 201 a 500 empregados; 4\%, de 501 a 1000 empregados e 5\% nas empresas com mais de 1.000 empregados.

Sabe-se que esse sistema de cotas em nosso país não tem possibilidade de assegurar emprego para todas as pessoas com deficiência que querem trabalhar. Estas são contadas em muitos milhões, enquanto que as vagas resultantes das cotas são pouco mais de 500 mil, situadas principalmente nas empresas com mais de 1.000 empregados.

Ademais, a implementação de tal política afirmativa é um desafio complexo, pois diz respeito a vários aspectos do mundo do trabalho e dos sujeitos envolvidos.

Origina-se de Aristóteles (1979) a formulação do princípio de "tratar igualmente os iguais e desigualmente os desiguais, na medida em que eles se desigualam", recuperado entre nós por Barbosa (1949), que adicionou que "tratar com desigualdade a iguais, ou a desiguais com igualdade, seria desigualdade flagrante, e não igualdade real”. As políticas afirmativas seguem esta lógica de promover a igualdade real. 
Para Rioux e Zubrow (2001), os estudos que analisam a deficiência como uma questão social têm algumas características comuns: assumem que a deficiência não é inerente ao indivíduo, independentemente da estrutura social; dão prioridade a aspectos políticos, sociais e ambientais; reconhecem a deficiência mais como uma diferença do que como uma anomalia; tratam da inclusão das pessoas com deficiência como uma responsabilidade pública e não como uma questão do âmbito individual; destacam as condições sociais, ambientais e econômicas como ponto primário de intervenção.

Neste artigo, o autor, considerando a insuficiência das estratégias de inclusão no trabalho adotadas no Brasil (FRANCA; PAGLIUCA; BAPTISTA, 2008), propõe-se a identificar e analisar em que medida as políticas de obtenção, garantia e progressão de trabalhadores com deficiência física os tem incluído no mundo do trabalho, reservando atenção especial ao sistema de cotas de emprego enquanto estratégia principal das políticas públicas. Para tanto, busca conhecer e analisar a trajetória dessas pessoas até conseguirem o emprego e as suas relações de trabalho, verificando como esses trabalhadores veem as políticas das empresas na seleção, incorporação, manutenção e progressão das pessoas com deficiência, bem como as medidas para adequação das barreiras físicas, sociais e culturais existentes.

\section{Procedimentos metodológicos}

O presente artigo origina-se, em parte, da tese de doutoramento do autor. Caracteriza-se, neste particular, como um estudo exploratório.

Inicialmente, pretendeu-se estudar um banco público e a trajetória de vida dos trabalhadores residentes em Salvador (Bahia) e em cidades próximas que ingressaram através de vagas para deficientes no último concurso da instituição, que admitiu, na Bahia, 9 pessoas pelo sistema de cotas.

Após realizar algumas entrevistas no banco, foi possível concluir que conhecer a realidade de uma só empresa não ampliaria muito a visão do objeto que se buscava, restringindo-se à aplicação da política de emprego em uma empresa pública. O campo de estudo estendeu-se, então, para uma rede de supermercados de Salvador, que chegou a ter 44 pessoas portadoras de deficiência no ano de 2002.

Em seguida, chegou-se à conclusão de que seria preciso ir além da comparação entre duas empresas e seus empregados, que seria preciso conhecer outras situações de vínculo empregatício, o que levou o autor a buscar um grupo de empregados terceirizados nos Correios. Ao mesmo tempo, percebeu-se que não eram apenas as políticas públicas e as práticas das empresas que se deveria estudar, mas também as estratégias das pessoas com deficiência na busca do trabalho e da inclusão. Surgiu, então, a possibilidade de incluir uma juíza, ocupante de uma carreira diferenciada do Estado. Para conhecer a realidade de trabalhadores sem a inter- mediação de uma organização, foi incluído um casal de comerciantes e profissionais liberais.

Para maior aproximação com a questão da inclusão das pessoas com deficiência, foram feitas visitas a instituições de Salvador, relacionadas ao tema, de modo a verificar também o grau de mobilização das pessoas com deficiência e o processo de capacitação para o trabalho. Foram realizadas visitas à Associação Baiana de Cegos (ABC), à Associação de Pais e Amigos de Deficientes Auditivos do Estado de Bahia (Apada), à Associação de Pais e Amigos dos Excepcionais de Salvador (Apae), à Associação Baiana de Deficientes Físicos (Abadef), ao Centro de Reabilitação e Prevenção de Deficiências (CRPD), ao Instituto Pestalozzi da Bahia e à Coordenadoria de Apoio ao Portador de Deficiência da Prefeitura Municipal de Salvador (Codef). Nessas instituições foram entrevistados seis técnicos e dirigentes. Posteriormente, foi entrevistado um dirigente de entidade de deficientes visuais para complementar dados sobre o mercado de trabalho, uma vez que este atuava em projeto apoiado pelo Ministério do Trabalho.

Por fim, a população de estudo foi constituída de 35 pessoas: 22 trabalhadores com deficiência, 6 chefes ou colegas de trabalho desses deficientes e 7 técnicos ou dirigentes de instituições relacionadas à deficiência.

O processo de coleta foi realizado no ano de 2003 com a colaboração de uma estudante de Psicologia, com experiência e devido treinamento, utilizando-se roteiros de entrevista semiestruturada, desenvolvidos a partir de modelo elaborado por Costa (2001a). No decorrer da coleta, flexibilizou-se um pouco mais o uso dos roteiros, permitindo um maior enriquecimento dos depoimentos à medida que os entrevistados não se sentiam presos a uma determinada questão. As 6 entrevistas com técnicos e dirigentes, realizadas nas instituições, foram baseadas em um roteiro específico sobre as atividades e características dessas entidades.

As entrevistas foram gravadas ou anotadas. Os seguintes tópicos foram abordados na entrevista com os deficientes: a) nascimento e infância (data de nascimento, número de irmãos mais velhos ou mais novos, idade dos pais, onde passou a infância, brincadeiras, amigos, escola); b) adolescência (amigos, escola, namoros); c) família (maiores vínculos, situação financeira, apoios); d) trabalho (profissionalização, experiências anteriores); e) deficiência (se adquirida, principais mudanças na vida, nos projetos pessoais, nas relações sociais e afetivas, participação em movimentos sociais); f) experiência de trabalho atual (mudanças na vida, relação com amigos e colegas, análise crítica e acessibilidade).

O Quadro 1 apresenta dados relativos aos 22 deficientes físicos entrevistados, dentre os quais: trabalhadores de banco, supermercado, terceirizados numa empresa estatal (Correios), dois comerciantes, juíza, professor e psicóloga. A mediana de idade das pessoas com deficiência entrevistadas foi de 33 anos, variando de 24 a 53 anos. Dentre os admitidos pelo sistema de cotas, tal mediana é um pouco menor $(31,5)$, sendo que neste grupo a mediana entre as mulheres $(31,5)$ é maior 
que entre os homens (30,5). Em relação ao gênero, 46,3\% das mulheres obtiveram trabalho pelo sistema de cotas, proporção que, entre os homens, ficou em 44,4\%. O quesito ocupação, como visto, foi diretamente influenciado pelo processo de escolha da população de estudo.

À exceção de um bancário que trabalha e mora na região de Feira de Santana, todos os entrevistados residiam em Salvador e seus locais de trabalho eram lojas de uma rede de supermercados, agências de um banco público, a agência central dos Correios, o Poder Judiciário, uma faculdade privada, um consultório e uma pequena loja.

As atividades profissionais exercidas foram as seguintes: 4 escriturários em banco público; 8 auxiliares administrativos (7 como terceirizados nos Correios e 1 num supermercado); 1 professor universitário; 4 operadoras de caixa de supermercado, uma das quais recémaposentada por invalidez; 1 operador de computador (em supermercado); 2 comerciantes (pequenos empresários); 1 psicóloga (autônoma); 1 juíza.
Foram ainda entrevistados 6 chefes e colegas desses trabalhadores com deficiência, assim como 7 técnicos e dirigentes de instituições relacionadas à deficiência, totalizando 35 entrevistas. Não foi elaborado um quadro-resumo referente a estes entrevistados tal como o Quadro 1 relativo às pessoas com deficiência.

As entrevistas com os chefes e os colegas de pessoas com deficiência abordaram os seguintes tópicos: a) tempo que chefiou/trabalhou com as pessoas com deficiência; b) experiência anterior de trabalho com pessoas com deficiência; c) como percebia o desempenho profissional das pessoas com deficiência em relação aos demais colegas; d) como se dava a relação de trabalho; e) oportunidades de manutenção e progressão no emprego das pessoas com deficiência; f) medidas adotadas pela empresa para adequação das barreiras físicas, sociais e culturais que pudessem dificultar a incorporação das pessoas com deficiência; g) medidas que devem ser adotadas pelas políticas públicas para a inclusão no trabalho.

Quadro 1 Dados pessoais dos entrevistados com deficiência física

\begin{tabular}{|c|c|c|c|c|c|}
\hline Pseudônimo & Sexo & Idade & Ocupação & Vínculo & $\begin{array}{c}\text { Admitido devido à } \\
\text { política de cotas }\end{array}$ \\
\hline Ademar & M & 26 & Escriturário & Banco & $x$ \\
\hline Ana Maria & $\mathrm{F}$ & 29 & Auxiliar administrativo & Correios & \\
\hline Beatriz & $\mathrm{F}$ & 31 & Operadora de caixa & Supermercado & $x$ \\
\hline Carla & $\mathrm{F}$ & 30 & Auxiliar administrativo & Supermercado & $x$ \\
\hline Cícero & M & 40 & Escriturário & Banco & $x$ \\
\hline Cintia & $\mathrm{F}$ & 53 & Juíza & Governo Federal & \\
\hline Daniela & $\mathrm{F}$ & 43 & Comerciante & Pequeno empresário & \\
\hline Djalma & M & 33 & Operadora de computador & Supermercado & $x$ \\
\hline Egídia & $\mathrm{F}$ & 36 & Auxiliar administrativo & Correios & \\
\hline Eliana & $\mathrm{F}$ & 29 & Operadora de caixa & Supermercado & $x$ \\
\hline Eraldo & M & 49 & Comerciante & Pequeno empresário & \\
\hline Ivana & $\mathrm{F}$ & 34 & Operadora de caixa & Supermercado & $x$ \\
\hline José Américo & M & 25 & Auxiliar administrativo & Correios & \\
\hline Jussara & $\mathrm{F}$ & 52 & Psicóloga & Autônomo & \\
\hline Larissa & $\mathrm{F}$ & 46 & Auxiliar administrativo & Correios & \\
\hline Nelma & $\mathrm{F}$ & 46 & $\begin{array}{l}\text { Operadora de caixa (aposentada } \\
\text { por invalidez) }\end{array}$ & Supermercado & $x$ \\
\hline Oscar & M & 28 & Escriturário & Banco & $x$ \\
\hline Paulo & M & 38 & Psicólogo & Professor & \\
\hline Sandro & M & 24 & Auxiliar administrativo & Correios & \\
\hline Sérgio & M & 33 & Auxiliar administrativo & Correios & \\
\hline Silvana & $\mathrm{F}$ & 31 & Auxiliar administrativo & Correios & \\
\hline Suzana & $\mathrm{F}$ & 32 & Escriturária & Banco & $x$ \\
\hline
\end{tabular}


Nas entrevistas com lideranças de entidades relacionadas às pessoas com deficiência, foram abordados os seguintes itens: a) medidas que as empresas precisam tomar para adequação das barreiras físicas, sociais e culturais; b) políticas públicas e inclusão no trabalho das pessoas com deficiência; c) diferenças de oportunidades de seleção, incorporação, manutenção e progressão na carreira; d) sistema de quotas; e) habilitação profissional pelas entidades não governamentais. E, nas visitas às instituições da área, foram verificados, dentre outros, os seguintes aspectos: tipo de instituição; instalações; horário de funcionamento; fonte de financiamento; perfil da clientela-alvo; atividades associativas e assistenciais desenvolvidas; atividades relacionadas à integração no mercado de trabalho.

O autor obteve um termo de consentimento com informações de todos os entrevistados e os nomes destes foram alterados de modo a preservá-los. O trabalho foi aprovado pelo comitê de ética em pesquisa do Instituto de Saúde Coletiva da Universidade Federal da Bahia.

Os textos originados da degravação das entrevistas foram analisados com base em categorias que visaram abranger aspectos relacionados à vida familiar, ao corpo e à identidade, ao trabalho como fator de inclusão, às relações no trabalho e à acessibilidade. A análise do discurso levou em conta ainda as informações coletadas nas instituições visitadas e a experiência do autor na avaliação médica de trabalhadores com deficiência.

Foram selecionados trechos das entrevistas que melhor ilustravam a concepção mais prevalente em relação a cada uma das questões. Não foi feita a correção gramatical nos depoimentos citados no texto, mantendo-se, quanto possível, a transcrição literal das falas.

Foram revisadas as convenções e os programas dos organismos internacionais e os documentos legais e de políticas públicas do Brasil. Para desenvolver sua análise, os arquivos foram organizados por tipo e origem, foram elaboradas fichas de leitura e identificadas com termos ou palavras-chave, anotando-se observações ou comentários sobre as questões relacionadas à inclusão de pessoas com deficiência no trabalho.

Foram ainda analisadas as estatísticas de emprego, disponibilizadas pelo Programa de Disseminação das Estatísticas do Trabalho (PDET) do Ministério do Trabalho e Emprego (BRASIL, 2009).

\section{Trabalho como meio de inclusão}

Segundo dados do Ministério do Trabalho e Emprego (BRASIL, 2009), os trabalhadores com deficiência ocupam menos de $1 \%$ dos empregos formais no Brasil. O que significa que avançamos pouco em relação ao necessário.

Em relação ao sistema de cotas, vê-se que as empresas com mais de 100 empregados, que representam cerca de $10 \%$ do total de empregos no país, têm ampliado os vínculos formais de trabalhadores com deficiência, número que chegou a 74,96\% (261.458) dos 348.818 trabalhadores com deficiência, com vínculo formal em 2007. Em 2000, essa proporção era de $69 \%$ dos trabalhadores que estavam na empresas com mais de 100 empregados. Tal distribuição não se faz de maneira linear nas empresas obrigadas a cumprir a cota, algumas delas superam as cotas legais e outras ficam abaixo, enquanto que as maiores empresas cumprem menos a cota do que aquelas que possuem entre 100 e 500 empregados (BRASIL, 2009).

Dados do Ministério do Trabalho registram que, em 2002, a Bahia tinha 28.155 pessoas com deficiência empregadas, o que representava $2,4 \%$ dos trabalhadores formais no estado. Em anos recentes, as empresas baianas informaram, em relação às cotas para pessoas com deficiências, a contratação de 720 trabalhadores em 2006 (6,32\% do total nacional de contratações nas cotas), 837 trabalhadores em 2007 (6,91\%) e 684 trabalhadores em 2008 (6,21\%). Esses dados revelam que o estado tem tido um número de contratações acima da média nacional, todavia não permitem afirmar se são vagas novas ou simples substituição de trabalhadores com deficiência, que já estavam no mercado formal.

No presente estudo, todos os entrevistados conhecem a política de cotas e a maioria considera que é uma iniciativa importante para ampliação do mercado de trabalho para as pessoas com deficiência, todavia, alguns apontam críticas ou identificam a necessidade de medidas complementares. Alguns dos depoimentos selecionados demonstram, a seguir, como persiste importante controvérsia sobre a política.

Larissa, terceirizada nos Correios, em vaga que não foi criada pelo sistema de cotas, surpreende ao afirmar que agradece por ter a sequela de poliomielite que traz desde a infância, pois, "graças a ela" conseguiu o atual emprego:

Agradeço ter tido essa deficiência, porque diante da lei, do mundo de hoje, que nós vivemos, é obrigatório que a gente, como portador de necessidades especiais, que atua no mercado de trabalho, então me sinto até gratificada por isso, porque antes, como eu tinha complexo, me sentia assim inferior. Hoje me sinto até, de uma certa forma, superior, porque posso trabalhar. Eu tenho direito. (Larissa)

A deficiência é a condição que lhe deu acesso ao emprego e, portanto, é vista como positiva para a sua vida. Não se trata de um "orgulho de ser deficiente", nem da utilização da deficiência como se fosse uma arma, mas do fato da deficiência ter sido sua compensação pela desvantagem que tem por conta da posição social e do gênero. Ironicamente, aquilo que era defeito torna-se virtude para ela.

A questão de fundo, todavia, é o conceito de justiça que deve prevalecer em nossa sociedade: distributiva (que se baseia na igualdade) ou meritocrática (que premia ou castiga o desempenho individual).

Em última instância, a emancipação de grupos discriminados se dará plenamente com a emancipação da 
própria sociedade, que os constitui enquanto problema social (MARX, 1968), o que, evidentemente, não deve ser justificativa para que não sejam buscadas medidas transitórias e avanços parciais.

Segundo Rawls (1997), para que tenhamos uma sociedade mais justa, é preciso que haja justiça com equidade, ou seja, garantindo proteção especial do Estado às minorias e àqueles que estão em desvantagem. Embora se baseie na suposição de um "homem racional" e moral, numa "sociedade de cooperação social" entre pessoas livres e iguais, traz elementos essenciais para que se desenvolvam políticas de inclusão.

Silvana, terceirizada dos Correios, afirma que houve ampliação no mercado de trabalho para pessoas com deficiência e atribui isso ao sistema de cotas:

Antes os deficientes não podiam trabalhar porque iam pra as empresas pedir emprego e eles fechavam a porta, mas agora, com essa lei, eles não podem mais fechar a porta pro deficiente.

Eliana, caixa do supermercado, tem opinião semelhante: "eu acho que, se não tivesse essa lei, ia ser bem mais difícil a inclusão do deficiente no mercado de trabalho".

Sérgio, terceirizado dos Correios, argumenta que o processo é demorado, pois, para ele, as empresas ainda não estão preparadas para receber as pessoas com deficiência e não as aceitam por preconceito. Acha que, aos poucos, as empresas estão se adequando porque são fiscalizadas e, com isso, as pessoas com deficiência mostrarão que são tão "capazes quanto qualquer outra pessoa normal”. Mas critica as empresas que tentam burlar a lei, incluindo como deficientes "até com pessoas que têm pressão alta”. Sucessivas regulamentações têm buscado evitar lacunas na legislação, evitando que as empresas possam contratar, nas cotas, trabalhadores que não são legalmente caracterizados como pessoas com deficiência.

Oscar, que tinha dificuldade em conseguir emprego antes de ingressar por concurso no banco, defende o sistema de cotas, mas diz que não basta obrigar as empresas a terem vagas, é preciso adotar várias outras medidas:

Deve ter também o cuidado de ver se o deficiente está tendo acesso à educação. Não basta apenas, sendo deficiente, existir a cota de $5 \%$, é preciso ver se tenho escolaridade pra isso, se tive a oportunidade de chegar até a escola. A gente sabe que existe passe pra deficiente físico pegar um ônibus e não precisar pagar o transporte. Mas às vezes é complicado pra ele descobrir um ônibus onde ele possa ser levado pra escola. Ou descobrir uma escola que ele possa estudar e que tenha facilidade de acessar, porque tem elevador em shopping, tem elevador em hotel, mas é difícil uma escola que tenha. Então, antes de você se preocupar em colocar o deficiente no mercado de trabalho, tem que preparar ele para o mercado de trabalho, e isso eu acho que está faltando. (Oscar)

É interessante observar que Oscar destaca as dificuldades de acesso à educação mesmo tendo, ele, sido aprovado num concurso para o qual se exigia o mínimo de $2^{\text {o }}$ grau completo, o que, por si só, já eliminou grande parte das pessoas com deficiência sem acesso à educação formal.

Marcelo, 44 anos, chefe imediato de Oscar, opina que as cotas são uma necessidade temporária, enquanto não há uma "evolução educacional, de cabeça”, no país.

Carla não ingressou como deficiente no supermercado, tendo sido incorporada na lista posteriormente à regulamentação das cotas, porque "a empresa precisava cumprir a lei”. Ela fala com entusiasmo e pouca crítica da possibilidade do sistema de cotas ampliar o mercado de trabalho:

É muito bom, é muito prazeroso saber que pessoas que estão ali, sem esperança, vão conseguir alguma coisa, alguém [que] olhe por elas, saber que a empresa está olhando por elas e querem aproveitar elas de alguma forma.

Djalma, que trabalha como operador de computador na mesma loja de Carla, fala que: "nunca me considerei ou me consideraram deficiente. A loja estava com dificuldade de completar o número mínimo de deficientes e como disse que tenho uma diferença de uma perna pra outra, eu fui examinado pelo médico", revelando que vagas são ocupadas por pessoas que não apresentam deficiência ou incapacidade, caracterizando mais um exemplo de burla à legislação.

O depoimento de Luciano, gerente de Recursos $\mathrm{Hu}-$ manos da rede de supermercados, que já tinha experiência anterior em contratar pessoas com deficiência em outra empresa, apresenta dados que demonstram que o supermercado já empregava pessoas com deficiência desde 1996, antes da regulamentação da lei das cotas: "Já tínhamos uma cota moral, agora temos que atingir essa meta”. Luciano aponta a ação como de importante cunho social por parte da empresa, dentro da qual "sempre procurei trabalhar, contratar muito mais que as pessoas que as cotas nos propunham”, mas admite que nem sempre consegue manter as pessoas na loja.

Apesar da sua posição gerencial superior e de ter facilitado, de diferentes formas, o acesso do autor ao supermercado, sua autorização não impediu que uma supervisora criasse dificuldades e censurasse a entrevista com uma das trabalhadoras com deficiência, sem razão aparente a não ser a defesa da empresa perante uma entrevista que, a seu ver, poderia prejudicar os empregadores.

Marcos, 40 anos, chefe de várias operadoras de caixa de uma das lojas do supermercado, diz que a cota poderia ser até maior, mas, contraditoriamente, afirma que não gosta de cota, porque é uma forma de discriminar: "pra mim todas as pessoas são iguais, o espaço deveria ser aberto independente de cota". Falando do bom relacionamento e do desempenho de trabalhadores com deficiência, Marcos afirma que "por ter passado essa experiência com essas pessoas boas, acho que não deveria haver cota, independente de cota ou não, esse pessoal deveria ser aproveitado nas empresas", defendendo, assim, o sistema de méritos, que, como vimos, não garante a equidade. 
Paulo, professor, é crítico em relação à efetividade das cotas, cita o exemplo do hospital onde trabalhou, no qual não havia cotas e afirma que:

A maioria das leis no Brasil em relação à deficiência não são cumpridas. Essa coisa simples do percentual, poucas empresas fazem. Eu acho que sou o único professor deficiente aqui na universidade, e olha quantos professores.

A crítica de Paulo quanto ao não cumprimento da legislação se evidencia no fato de que a unidade de saúde que menciona é um hospital público de reabilitação que chegou a ter mais de 700 empregados e apenas ele apresentava deficiência.

Embora defenda o sistema de cotas, Egídia, operadora de caixa do supermercado, diz que $5 \%$ é muito pouco e que "geralmente as empresas não botam ninguém”. "Devia ter concurso só pra deficientes." Contradizendo-se, todavia, defende que: "Deviam aposentar as pessoas com deficiência grave, dar muleta, cadeira de rodas [...]”. Nelma afirma que a lei não vai garantir proteção, mas "é um meio de facilitar, porque nem toda empresa quer deficiente trabalhando, não”. A história de trabalho dela chama atenção para a questão da proteção no trabalho das pessoas com deficiência: ingressou, com deficiência nos membros inferiores, no trabalho de operadora de caixa num supermercado e ali desenvolveu tendinite de membros superiores, em razão do que foi aposentada por invalidez.

Ana Maria, que trabalha nos Correios, preferia que não houvesse a necessidade do sistema de cotas. Para ela, defendendo o sistema de méritos, "se não olhassem o físico, mas sim o desempenho nas provas ou entrevistas, era uma maneira melhor de oferecer oportunidades sem discriminar".

Jussara, colega de Ana Maria, vê a cota como discriminação: "É uma forma de entender que o deficiente não tem condição de enfrentar uma competição com os outros, está ajudando, mas também está discriminando”. Também José Américo, que não ingressou nos Correios pelo sistema de cotas, aponta a existência de discriminação no sistema de cotas:

Porque se você tem 50 deficientes que se inscrevem, que são mais capazes do que 50 pessoas que são normais, não têm deficiência, e você só pode colocar cinco das pessoas que são deficientes, eu acho que isso é uma discriminação muito grande.

Percebe-se aqui, novamente, que o argumento do mérito é o mais utilizado para contestar o sistema de cota, ignorando ou ocultando a situação real de desvantagem vivida pelas pessoas com deficiência.

Eraldo e Daniela, ambos pequenos comerciantes, defendem o sistema de cotas. Ele se entusiasma com a possibilidade de se garantir vagas para centenas de milhares de pessoas no país. Daniela pondera que muitos deficientes não querem trabalhar, "vivem em depressão, querem morrer, que não servem mais para nada”. Eraldo argumenta que isso acontece com deficiências mais graves, como os paraplégicos, mas "tem muita gente que procura trabalho, por exemplo, os surdos-mudos e os cegos também”. Opina que os cegos sofrem mais preconceito do que os deficientes físicos: "Se não for numa carreira própria, num empreendimento próprio, acho que dificilmente eles arranjam emprego".

Erasmo, que tem deficiência visual e é dirigente de uma associação, defende a reserva legal de vagas enquanto política afirmativa, que tem um papel de inclusão social a cumprir, mas conclui que ela é insuficiente, pois, ainda que estivessem garantidas todas as vagas previstas na lei, existem "as barreiras arquitetônicas, as barreiras urbanísticas, as barreiras sociais, a necessidade de capacitação”. Argumenta ainda que:

A lei peca no sentido de que "tem que colocar", dá os percentuais, identifica os tipos de deficiência, mas não diz quem é que vai capacitar, porque tem uma demanda que é de baixa renda, de pouca escolaridade, que não tem capacidade de pagar um curso de capacitação, então essas pessoas vão continuar fora do mercado. (Erasmo)

Francisco, 41 anos, chefe imediato de Ademar no banco, acha que tem que se criar essas cotas: "não diria que pra corrigir [as desigualdades], mas pra que talvez com isso fizesse uma correção no futuro”.

Garantir as cotas é uma forma de reparação da sociedade com as pessoas que têm deficiência, defende Suzana:

Pessoas que não vão ter um outro tempo para recuperar, e talvez mesmo que a sociedade mude de uma hora pra outra, dê oportunidade a essas pessoas, e que coloque uma cidade acessível, escolas acessíveis, professores bem capacitados, uma reabilitação decente, quando essas pessoas estiverem aptas, talvez elas já estejam velhas, já passou o tempo delas, então eu vejo que é uma forma de reparação necessária para com essas pessoas. (Suzana)

Tendo ingressado no banco, em vagas reservadas no concurso para pessoas com deficiência, Suzana diz que ela, que tem tetraplegia, tem a vantagem de ter formação universitária, o que não acontece com a maioria das pessoas.

Tatiana, 34 anos, chefe imediata de Suzana no banco, ressalta, com relação à reserva de vagas, que:

Não foi uma coisa de consciência que a empresa resolveu [...] então, acho que quando não tem a consciência, você tem que realmente fazer meio obrigado. Se não fosse isso, o banco não abriria vaga pra ela, ela não teria feito o concurso. Eu acho que a vida dela melhorou muito depois que ela veio pra cá. (Tatiana)

Apesar das críticas ao sistema de cotas, não são oferecidas alternativas que não passem por políticas afirmativas, que permitam que, sem a garantia de direitos especiais, as pessoas com deficiência possam ingressar e se manter no mercado de trabalho. Contudo, percebe-se nos depoimentos que as cotas isoladamente têm pequena capacidade de sucesso, caso não estejam articuladas a outras políticas sociais. 
O sistema de cotas, em si, encerra conflitos, porque envolve controvérsia na definição por parte de legisladores, médicos e gestores sobre quem é ou não deficiente. Cícero viveu intenso conflito após ser aprovado no concurso do banco e deixar o serviço de despachante numa empresa de ônibus: embora caracterizada sua deficiência física e considerado apto para o trabalho, sua admissão foi inicialmente recusada sem que lhe fossem formalmente explicados os motivos, a não ser uma informação verbal de que ele não era deficiente. Depois de ingressar com um recurso administrativo, outra avaliação foi feita e ele foi admitido, ficando a certeza de que foi discriminado, mas sobre o que prefere não mais falar.

Os órgãos normativos federais, ao longo dos anos, têm tentado tornar mais claros os critérios de caracterização como deficiente, processo que, obviamente, não será suficiente para eliminar os conflitos, dada a variação de conceitos de normalidade e deficiência.

\section{O bom trabalhador deficiente}

Desde a formação do capitalismo, para viabilizar a subjugação do trabalho ao capital, são elaborados mecanismos de controle do trabalhador. No início do século passado, os mecanismos de controle chegaram ao auge e os industriais utilizavam todas as formas para exaltar o "bom trabalhador", aquele que dedicava todas as suas energias ao trabalho, evitando excessos em relação aos seus afetos e prazeres (TUMOLO, 2003).

Nos dias de hoje, a figura do "trabalhador-padrão" continua sendo utilizada como forma de controle e aumento da produtividade. É interessante observar que se uma pessoa com deficiência tem boa produtividade no trabalho, termina cumprindo esta função simbólica do "bom trabalhador".

Todos os colegas e chefes entrevistados enfatizam o bom relacionamento e o bom desempenho que as pessoas com deficiência têm no trabalho. Embora considerem a deficiência um "problema”, destacam que essas pessoas são exemplos para as demais por conta do seu esforço de superação. Chega a ser uma ironia que o deficiente, antes símbolo da fragilidade, seja transformado em dispositivo vivo de disciplina e de controle do trabalhador.

\begin{abstract}
Acho que pra todo mundo aqui [Suzana] é um exemplo, [porque] dá para a gente a força e coragem que ela tem. Porque ela podia estar em casa. Tudo pra ela é muito mais difícil, mas ela enfrenta. Sair de casa, para ela, é uma luta. E ela vem, ela enfrenta [...], então, às vezes a gente chega assim meio cansado ou de mau humor, aí eu lembro logo dela. "Como é pra ela sair de casa num dia de chuva, o transporte não veio, faz o quê?”, eu lembro que pra ela é muito mais difícil. Então eu acho que pra todo mundo aqui ela é um exemplo, e todo mundo pensa nisso com certeza. (Tatiana)
\end{abstract}

Nessa linha, Luciano, gerente de Recursos Humanos de supermercado, mesmo relutando em comparar as pessoas com deficiência com as demais, ressalta que eles têm "mais compromisso e maior poder de concentração".
Francisco, chefe de Ademar no banco, diz que há com este um "elo de ligação", até de amizade, "o pessoal inclusive o estima, acha ele um exemplo de pessoa. Todo mundo tem o maior respeito profissional por ele”. Dá ênfase a um fato com frequência mencionado de que as pessoas com deficiência, por terem poucas oportunidades, se apegam ao trabalho com mais abnegação: "Ele talvez seja o que mais procura se comprometer, muito mais do que muitos outros que não têm nenhuma deficiência”.

A relação entre as pessoas com deficiência e seus colegas e chefes, muitas vezes, é revestida de tensões próprias do estranhamento em relação ao desacreditado ou desacreditável, como refere Goffman (1988). Mesmo relacionamentos tidos como normais, como entre $\mathrm{Su}$ zana e sua chefe Tatiana, são permeados de cuidados, inseguranças e sutilezas:

É tranquilo o relacionamento aqui, e às vezes eu até procuro [...] ajudar sem melindrar a pessoa. Ela não diz o que está precisando. Eu me policio pra observar se ela quer alguma coisa, às vezes ela fica mais calada [...], essas coisas, e não diz nada. Hoje mesmo ela estava se sentindo mal. Eu percebo quando ela fica calada, porque ela não diz, ela não pede ajuda. (Tatiana)

Luciano fala sobre o estranhamento quando compara os deficientes físicos com os surdos que trabalham no supermercado, referindo a dificuldade que estes têm de manter um bom relacionamento com os colegas. Afirma que, por ter uma linguagem diferente, o surdo "tem um mundo totalmente diferente":

Eles casam entre si, [com] algumas exceções, saem pra almoçar e [só] conversam entre si, então eu acho que eles é que sofrem este maior distanciamento, essa maior barreira. $\mathrm{O}$ deficiente físico não. $\mathrm{O}$ deficiente físico é totalmente engajado na vida profissional, tem amizades. (Luciano)

Lembra, porém, que, se o surdo não procura as outras pessoas, "a recíproca também é verdadeira, as pessoas que não têm deficiência também não procuram ele, dada a dificuldade do diálogo", e completa que "a deficiência física nada impede”.

Marcos, chefe de operadores de caixa no supermercado, tem um discurso dúbio de igualdade quando diz que todos no supermercado são tratados com igualdade e que "eles não são vistos como deficientes", retificando em seguida que: "são deficientes, mas o grupo tem uma relação boa, não existe isso, aqui existe um respeito muito grande para com as pessoas, eles já são adaptados”.

O conceito de que os desiguais devem ser tratados desigualmente é de difícil assimilação no cotidiano. Isso está expresso no depoimento de Beatriz, chefiada por Marcos, ao confirmar que "aqui, todo mundo é tratado como igual" e que quando surgiu um boato de que as pessoas com deficiência corriam risco de demissão, "o chefe disse [que] a gente tem mais capacidade que uma pessoa normal, vocês não podem se considerar pior do que ninguém, vocês trabalham certo". E conclui: "Então foi esclarecido isso, que a gente é igual a qualquer pessoa”. 
A forma de garantir o respeito às pessoas com deficiência pode ser até através de ameaça aos demais trabalhadores: "Logo que eu fui admitida aqui, o chefe disse a gente que não aceitava que ninguém desfizesse da gente e que até um olhar estranho teria uma punição" (Beatriz).

O relato de Beatriz, além de novamente trazer a utilização do exemplo do bom trabalhador, revela outra ironia da desigualdade: o fato dos trabalhadores serem ameaçados de demissão para tratar os colegas sem discriminação e com igualdade.

Uma ação que proporcione às pessoas com deficiência melhores condições de inclusão no trabalho pode ser também vista como privilégio e produz tensão entre os trabalhadores:

Quando eu entrei aqui, tinha umas meninas que eu até parei de ter amizade, porque eu senti que elas acharam ruim que a gente já entrou como operadora, e elas eram empacotadoras, elas acham que elas deveriam passar pra operadora e a gente entrar como empacotadora. (Beatriz)

Ivana não admite a hipótese de que os colegas a tentem proteger e sente-se ofendida com isso: "Me proteger? Comigo eles sabem com quem estão bulindo".

Marcelo, chefe de Oscar, diz que:

Profissionalmente, eu acho ele normal, igual aos outros colegas. O problema da dificuldade de locomoção que ele tem não afeta muito não, ainda mais que a função que ele tá exercendo é como caixa, ele não precisa caminhar muito.

O próprio Oscar conta que, no início, teve que enfrentar a "superproteção" dos colegas, mas:

Na convivência, a gente vai colocando as coisas em seus lugares, e se algum funcionário novo chega, até acha que tem determinadas coisas que eu não deveria estar fazendo, mas, no geral, acho que depois se acostuma comigo.

Para Cíntia, que não se valeu do sistema de cotas para ingressar na carreira de juíza, "o trabalho foi um fator determinante para o exercício pleno como pessoa e como cidadã, [pois] sem ele eu acho que eu não seria a pessoa completa que eu sou hoje”. Como magistrada, ganhou, além da capacidade econômica, o poder de "dizer o Direito", uma particular "oportunidade de valorização pessoal e de elevação da autoestima”, como se a fragilidade de deficiente, repentinamente, se invertesse, transformando-se em força de grande valor simbólico.

\section{Identidade e inclusão}

Tentando encontrar uma identidade para controlar a expressão do seu corpo e acobertar sua deficiência, tornando-o, a seu ver, "mais aceitável", o bancário Cícero construiu um sujeito metódico. Comportava-se quase como um militar e, tentando simular uma normalidade física, cultivava tórax e braços musculosos e pedalava até vinte quilômetros todo dia na sua bicicleta para "ninguém notar o defeito".
A submissão do corpo à disciplina, ao controle do medo e da imagem, reorganizando hábitos e capacidades perceptivas, faz parte da busca do estereótipo masculino, como estudou Wacquant (2002) em relação aos lutadores de boxe e a sua gestão do "capital-corpo".

O corpo percebido é, até naquilo que mais parece mais natural (seu volume, seu talhe, seu peso, sua musculatura etc.), um produto social, que depende de suas condições de produção, através de diversas mediações, tais como o tipo de trabalho e os hábitos alimentares. As classificações que vigoram em nossa sociedade fazem com que sejam permanentemente contrapostas as propriedades corporais, estabelecendo tipos dominantes e dominados: magro/gordo, grande/ pequeno, elegante/grosseiro, leve/pesado, normal/deficiente etc. (BOURDIEU, 1999).

Fontes (2004) opõe duas categorias principais de corpos em nossa sociedade: o "corpo dissonante", seja ele deficiente, velho, gordo ou doente, e o "corpo canônico", ideal da sociedade de consumo, cheio de conotações estéticas e sensuais, produto e objeto de compra e venda.

Também neste sentido, idealizar ou discriminar o "bom trabalhador deficiente" é uma forma de excluí-lo de fato do processo de socialização e de enfrentamento das desvantagens impostas pela forma como a deficiência é tratada na sociedade.

A contribuição da família na construção de identidade, na organização de papéis, no estabelecimento de limites e na defesa através do apoio mútuo é essencial na trajetória de todos os entrevistados e encontra-se ali a primeira oportunidade de ser tratado como pessoa que tem capacidades e habilidades a serem reforçadas.

Uma das trabalhadoras com deficiência entrevistada, Silvana, cuja família tem um nível de educação formal maior que muitos dos entrevistados, relata sofrer acentuado grau de discriminação. Seu relato exemplifica como é complexa a construção desse suporte familiar, havendo necessidade de considerar elementos culturais, antropológicos e psicanalíticos.

O processo de inclusão envolve o indivíduo, a família, a sociedade e o Estado. Quando Nelma diz que sua mãe não queria que ela estudasse porque achava que não iria trabalhar ou mesmo casar, pois "um aleijado tinha que ser escondido da sociedade", registra uma atitude ainda comum na sociedade, que não se resolve apenas pela reação do indivíduo, mas por uma política pública de estímulo à inclusão, que envolva famílias, instituições e pessoas com deficiência como principais protagonistas.

A repercussão da deficiência nos projetos de vida, nas relações afetivas e sexuais aparece em muitas das entrevistas realizadas. Os projetos e desejos são reorganizados dentro de uma nova relação com a sociedade, nos novos pactos de interdependência. Muitos podem ser reprimidos, mas não são eliminados. 
Em relação à sexualidade na deficiência, Paulo destacou que "é um aprendizado totalmente novo e diferente", "não tem muita coisa escrita para você aprender, você vai aprender no contato com outras pessoas, por tentativa e erro, nas falhas". O tema da sexualidade é essencial na conquista da autoestima, mas tem sido pouco explorado nos estudos sobre a deficiência.

Por sua vez, a questão de gênero apareceu nas entrevistas em relação ao papel exercido pela mulher enquanto cuidadora, no preconceito relativo ao casamento da mulher deficiente, na dominação masculina presente mesmo quando marido e mulher apresentam a mesma lesão grave. Surge ainda no relato de Cícero, cuja masculinidade se expressa na sua extremada valorização do capital-corpo.

$\mathrm{Na}$ maioria das entrevistas aparecem indícios da questão de raça/etnia, o que não poderia deixar de se fazer presente numa cidade como Salvador, na qual $83 \%$ são afrodescendentes. O acesso à educação, ao trabalho e a bens e serviços em geral, essenciais para a definição da deficiência, tornam-se ainda mais difíceis quando se impõe a desvantagem racial. No caso da psicóloga Jussara, que recebe manifestações de solidariedade pelo fato de ter perdido um braço, mas é discriminada por ser negra, há uma clara demonstração de que a "opressão social" à pessoa com deficiência não pode ser analisada sem se levar em conta também a "opressão racial" marcante.

Nenhuma outra questão, entretanto, é mais mencionada que a acessibilidade, enquanto elemento essencial que fortalece a desigualdade de oportunidades. Este conceito, geralmente circunscrito à acessibilidade física, expressa a necessidade de termos uma cidade e uma sociedade em que todos tenham direito de ir e vir, de poder usufruir bens e serviços, de trabalhar etc. Mesmo a acessibilidade física já envolve uma série de restrições à pessoa com deficiência: para os que utilizam cadeiras de rodas e não podem transitar em passeios irregulares, para os deficientes visuais que se batem em telefones ou postes colocados no meio das calçadas ou para os deficientes auditivos, para os quais não há sinalização visual adequada no trânsito.

$\mathrm{O}$ direito à acessibilidade, em verdade, não torna uma sociedade verdadeiramente acessível a todos, mas minimiza as iniquidades existentes para as pessoas com deficiência, permitindo-lhes oportunidades até então inexistentes, abrindo espaços de autonomia e conquista de outros "direitos inacessíveis".

A autonomia individual, para Doyal e Gough (1994), é composta de três elementos-chave: o grau de compreensão que a pessoa tem de si mesma; a capacidade psicológica que possui de formular opções para si mesma; e as oportunidades objetivas que lhe permitam dar consequência a essas opções.

Este terceiro elemento é justamente aquele mais susceptível de ser ampliado, pois é a possibilidade de se obter oportunidades de "romper as cadeias da sua opressão”. A autonomia pode ser vista como uma necessidade básica dos indivíduos, mas também como um elemento de transformação, pois, a cada grau de autonomia conquistado, pode-se alcançar novas opções de autonomia, num sentido cada vez mais profundo de “autonomia crítica” (DOYAL; GOUGH, 1994).

\section{Conclusões}

A presença de um trabalhador com deficiência numa empresa contribui para redefinir papéis, mas não modifica a essência da organização do trabalho. Nos jogos de interesses e tensões existentes na empresa, provoca a discussão sobre a equidade e o mérito, assim como sobre as capacidades e os limites do trabalhador frente aos interesses da empresa.

Da mesma forma, para a pessoa com deficiência, há sempre uma desvantagem real que reduz a dimensão dos sucessos, das capacidades, questão essencialmente construída no campo social e simbólico.

Nas práticas de inclusão no trabalho, foram verificadas situações que podem ser denominadas como de "ironias da desigualdade", tais como: a ameaça de chefes a empregados, obrigando-os a tratar os deficientes como normais; a visão da deficiência como virtude, por facilitar o acesso ao emprego; e a utilização do deficiente, em razão da sua superação de limites, como exemplo de bom trabalhador e fator de disciplinamento (no sentido de internalização das regras produtivas). Estas questões apontam para a necessidade de um refinamento das políticas públicas e empresariais, de modo a viabilizar a efetiva inclusão no trabalho.

As estratégias de inclusão no trabalho adotadas em nosso país, apesar de alguns avanços, são ainda insuficientes e precisam ter em conta todos os variados aspectos do complexo mundo do trabalho, das pessoas e das instituições envolvidas.

O sistema de cotas é uma política afirmativa que precisa ser defendida, em especial num período de crise financeira e de empregos, que expõe todos os trabalhadores a uma grande vulnerabilidade, que se torna ainda maior no caso das pessoas com deficiência.

Não se pode imaginar que a reorganização social para eliminação de barreiras esteja apenas no terreno da legislação, da educação ou da cultura. São necessárias transformações mais profundas no campo da economia, da ideologia e da política. Mesmo barreiras arquitetônicas, que podem ser facilmente removidas num bairro de classe média ou alta, chegam a ser intransponíveis numa favela situada numa encosta, onde a sobrevivência é uma difícil conquista diária.

Por conta disso, qualquer política de inclusão de pessoas com deficiência tem que levar em conta que é na sociedade que se encontra a incapacidade maior de lidar com as diferenças corporais, de habilidades e de classes. 
Não se trata de imaginar que o enfrentamento da deficiência só é possível com a superação da diferença de classes, base fundamental da sociedade capitalista. Tal hipótese seria um adiamento de soluções para um além-horizonte que não é possível enxergar nos dias atuais. Porém, tanto quanto existem lesões que não são assimiladas apenas pela proposta de autonomia, existem barreiras sem perspectiva de solução.

Todavia, a própria palavra "barreira” dá a falsa ideia de que o que condiciona a deficiência é sempre algo externo às pessoas, mas a sociedade é feita de pessoas e o fato de algumas delas se apropriarem dos meios de produção e explorarem as outras é a maior de todas as barreiras.

A modificação das políticas públicas não se faz de modo espontâneo, mas por ações coletivas e solidárias voltadas à mobilização política e social e à pressão para que o Estado cumpra seu papel. A principal mobilização que ocorre no Brasil está relacionada ao sistema educacional e mais recentemente ao trabalho. Todavia, ainda prevalecem ações voltadas à educação especial e não à incorporação das pessoas com deficiência no sistema educacional universal.

O desenvolvimento de uma política pública de inclusão no trabalho exige não apenas a implementação do sistema de cotas como fator indutor de novas vagas e da discussão e mobilização em torno do tema. É também necessário um conjunto de medidas que envolvam a inclusão escolar, o estímulo à habilitação e ao desenvolvimento profissional, a reabilitação de pessoas vitimadas por acidentes ou doenças etc.

\section{Referências}

ARISTÓTELES. Ética a Nicômaco. São Paulo: Abril Cultural, 1979. (Coleção Os Pensadores)

BARBOSA, R. Oração aos moços. Rio de Janeiro: Casa de Rui Barbosa, 1949.

BASTOS, A. L. G. O adolescente com deficiência e seu processo de escolha profissional. Adolescência Latinoamericana, Porto Alegre, v. 3, n. 1, ago. 2002.

BAUMAN, Z. Comunidade: a busca por segurança no mundo atual. Rio de Janeiro: Jorge Zahar, 2003.

BOURDIEU, P. A dominação masculina. Rio de Janeiro: Bertrand Brasil, 1999.

BRASIL. Ministério do Trabalho e Emprego. RAIS

- Relação Anual de Informações Sociais, 2000 a 2007.

Disponível em: <http://www.mte.gov.br/pdet/index. asp>. Acesso em: 30 dez. 2009.

COSTA, V. A. A. A formação na perspectiva da Teoria Crítica da Sociedade: as experiências dos trabalhadores deficientes visuais do serviço federal de processamento de dados. 2001. 398 f. Tese (Doutorado, Programa de Educação, História e Filosofia da Educação)-Pontifícia Universidade Católica de São Paulo, São Paulo, 2001a.
As políticas públicas de emprego se completam, ademais, com parcerias crescentes com a iniciativa privada, visando ampliar ações de "responsabilidade social" e cumprir os deveres fixados na legislação, assim como habilitar pessoas com capacidade para realizar um sem-número de atribuições.

A questão da deficiência tem que passar a ser uma questão do interesse público e não apenas do âmbito privado, muito embora neste nível estejam mudanças importantes do ponto de vista cultural e ideológico. É preciso que haja desenvolvimento tecnológico e interesse do mercado, mas, acima de tudo, é indispensável que se busquem políticas de Estado abrangentes e que se conquiste uma sociedade menos injusta e mais equânime.

A luta pelo respeito às diferenças, ademais, não pode se confundir com a preservação das desigualdades. A conquista do direito humano à diferença não pode ofuscar a busca pela justiça social, sob pena de, contraditoriamente, ao nos fixarmos apenas no respeito às diferenças corporais ou funcionais, estimularmos a produção e a perpetuação das desigualdades sociais e econômicas as quais geram diferenças que aprofundam a deficiência.

Mais estudos sobre iniquidade e deficiência são necessários, não apenas no que se refere ao trabalho, mas em relação ao conjunto das políticas sociais, de modo a entender, do modo mais completo possível, como se dá a construção social da deficiência em nosso país e quais os caminhos necessários para reduzir ou eliminar as desigualdades.

. A formação do trabalhador com deficiência: questões acerca do trabalho, educação e emprego. Revista Escola. Rio de Janeiro, v. 2, n. 2, p. 52-60, 2001b.

DINIZ, D.; SQUINCA, F.; MEDEIROS, M. Qual

deficiência? Perícia médica e assistência social no Brasil. Cadernos de Saúde Pública, v. 23, n. 11, p. 25892596, 2007.

DOYAL, L.; GOUGH, I. Teoría de las necesidades humanas. Tradução de José Antonio Moyano e Alejandro Colás. Barcelona: Icaria/FUHEM, 1994.

DRACHE, D. Rethinking the very essence of social inclusion and things private. June, 2004, $24 \mathrm{p}$.

Disponível em: <http://www.yorku.ca/robarts/projects/ wto/pdf/rethinkingessence.pdf> . Acesso em: $30 \mathrm{dez}$. 2009.

FONTES, M. L. A. Corpos canônicos e corpos dissonantes: uma abordagem do corpo feminino deficiente em oposição aos padrões corporais idealizados vigentes nos meios de comunicação de massa. 2004. 222 f. Tese (Doutorado)-Faculdade de Comunicação da Universidade Federal da Bahia, Salvador, 2004. 
FRANCA, I. S. X.; PAGLIUCA, L. M. F.; BAPTISTA, R. S. Política de inclusão do portador de deficiência: possibilidades e limites. Acta Paulista de Enfermagem, v. 21, n. 1, p. 112-116, 2008.

FRANCIS, L.; SILVERS, A. Americans with disabilities. New York: Routledge, 2000, 432 p.

GOFFMAN, E. Estigma: notas sobre a manipulação da identidade deteriorada. 4. ed. Rio de Janeiro: Guanabara, 1988.

MARX, K. La question juive. Paris: Union Générale d'Éditions, 1968.

METTS, R. Disability issues, trens and recomendations for the World Bank. Feb 2000, 67 p. Disponível em: <http://www-wds.worldbank.org/servlet/
WDSContentServer/WDSP/IB/2001/12/11/000094946 01110204011328/Rendered/PDF/multi0page.pdf $>$. Acesso em: 30 dez. 2009.

RAWLS, J. Uma teoria da justiça. São Paulo: Martins Fontes, 1997.

RIOUX, M.; ZUBROW, E. Social disability and the public good. In: DRACHE, D. (Ed.). The market or the public domain?: global governance and the asymmetry of power. London: Routledge, 2001. p. 148-171.

TUMOLO, P. S. Trabalho, vida social e capital na virada do milênio: apontamentos de interpretação. Educação e Sociedade, v. 24, n. 82, p. 159-178, 2003.

WACQUANT, L. Corpo e alma: notas etnográficas de um aprendiz de boxe. Rio de Janeiro: Relume-Dumará, 2002. 